\title{
Rethinking the rituals in the Malay House
}

\author{
M. F. Kholid, S. S. Zubir \& R. Ab. Rahman \\ Centre of Studies for Architecture, Faculty of Architecture, \\ Planning and Surveying, Universiti Teknologi MARA Selangor, Malaysia
}

\begin{abstract}
The fact that the Malay rituals are practiced in daily life, rather than symbolically performed, insinuates the strong correlation of the traditional principle. The everyday life is a point of reference. It indicates the domestic sphere where the common and ordinary are projected, advocating the significance of dwelling as an artifact that spatially frames the rituals; in this case the traditional house where its evolution into modern dwelling acknowledges the multiple layering of the rituals' perception. This paper intends to analyze the performance of rituals and how these are spatially practiced in the modern context. Eleven traditional houses were investigated based on their interior layout. The 'Kampung Boy' series by Lat were used as a pictorial evidence of traditional lifestyle, reflecting the layout of the houses. Suggested embedded rituals, which are still significant in the present day are then represented in three manifestoes where the modern Malay house in Kuala Lumpur acts as the background and a single Malay family becomes the characters. These manifestoes were finally developed as critical tools and tested into three projects of low, medium and high-rise development. The dichotomy between traditionalist, idealist, and realist gave emergence to a new paradigm towards the representation of rituals in the modern Malay house. In fact, the projects were counterproposal of the existing housing scheme (particularly in Malaysia) where the notions of rituals altered the banality of standardization.

Keywords: rituals, spatial performance, artifacts, housing, development.
\end{abstract}

\section{Introduction}

The traditional Malay house is a living artifact that spatially frames the rituals. It implicitly projects the notion of rituals in everyday routine, which accentuates the Malays values and manner. In the ancient culture, the house allows the Malay to be 'decent', in terms of the social life, domestic culture, ethics, and religion [1]. 
Gender segregation and sitting rituals are the most important ritual extracted through its internal layout, which remain constant for almost 400 years, while the exterior façades absorb a variety of influences [2]. This scenario suggests that the rituals have been embedded into the daily life, hence projecting a persistent domestic spatial quality regardless of its location and influences. The evolution of the traditional house into modern form provided multiple stories pertaining to the performance of rituals. One may think that the generic modern layout accentuates 'zero' rituals. Yet, it allows the rituals to be transposed into the ordinary elements surrounding the life of its inhabitants [3]. This phenomenon can be extracted through the analytical studies of the modern Malays living, where the furniture and daily objects are curated within their embedded rituals.

\section{The origin}

Everywhere in the world, the traditional house is a 'genius loci' that personalised the region, and signifies the culture of a society. The Malay traditional house appears to be generic by applying similar construction system and having common interior spaces that consists of the 'anjung' or entrance, 'serambi' or reception area, 'rumah ibu' or main house, 'selang' or passageway and 'dapur' or kitchen [4]. However, if one looks further, the typology may be different; from the northern state to the southern part, the composition is in variance due to cross cultural influences through trading, migration, colonialism and water-based activities [5]. Figure 1 shows two (2) samples of the typological study of a Malay traditional house according to regions. In this analysis, there is justified evidence that consistency occurs in its interior space, suggesting that the Malays were obligated to certain rules, which dominate their culture and habits [6]. On the other hand, it was believed that the ancestors (through the housing layout) have imposed a domestic ritual, which implicitly deems to nurture and bind the society [2].

\section{The untold story of the Malay House interior}

A traditional house shall not be perceived as an edifice. As mentioned earlier, it disseminates rituals that perpetually confront the Malays' perception. For instance, the 'anjung' may act beyond the function of a conventional 'verandah'. It is a place for strangers to meet the occupants, a social place to get to know each other. This space is largely open, only enclosed by roof and columns. Hence, it gives a sign to the neighborhood that the owner is meeting someone who is an outsider, since the surrounding neighborhood is made up of close family relatives, who know each other very well. The 'anjung' is also a place for the men to meet up, normally before heading to work. Once a person is no longer a stranger, an invitation will direct (now acknowledged as) the 'visitors', to the 'serambi' area, which is also the living area of a house. Here, the conversation is more informal. Yet, this space is designated for the men, as women will be guided into a place called 'selang' situated in between the kitchen and 'Rumah Ibu' or main house. Openings between 'serambi' and 'Rumah Ibu' draw the limit between men and women's domain. 'Bendul', the threshold, is created at the openings as a physical device to mark the 
Pulau Pinang Traditional House

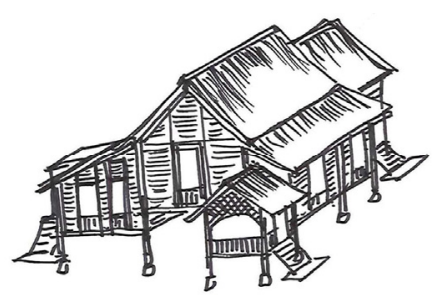

(a)

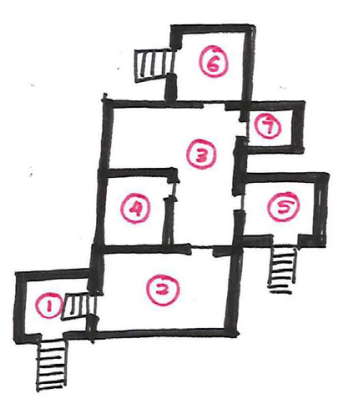

(c)

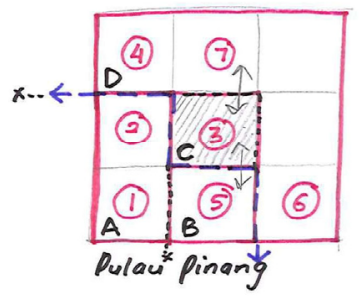

(e)

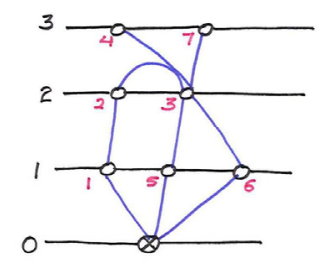

(g)
Johor Traditional House

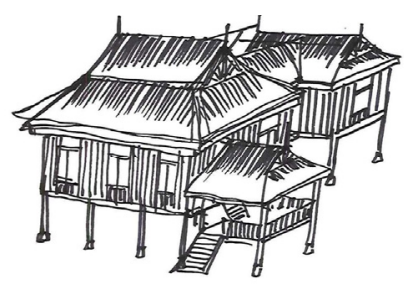

(b)

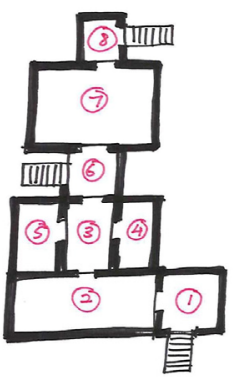

(d)

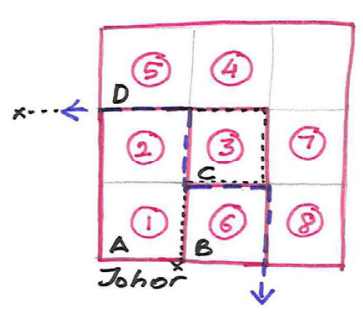

(f)

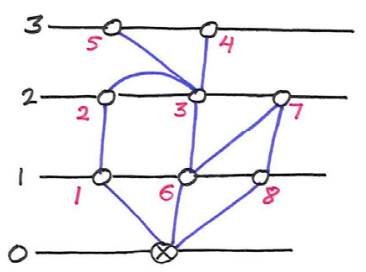

(h)

Figure 1: Two (2) samples from the 11 typological studies of the traditional house; Pulau Pinang House (a) in the northern region, Johor House (b) in the southern region. Interior layout (c), (d) consists of space 1: Anjung; space 2: Serambi; space 3: Rumah Ibu; spaces 4 and 5: bedroom/extra room; space 6: Selang; spaces 7 and 8: kitchen. (e) and (f) show the demarcation of public (A), semi-public (B and D), semiprivate $(\mathrm{C})$ and private $(\mathrm{D}) .(\mathrm{g})$ and $(\mathrm{h})$ show the interconnection of spaces as suggested by Markus [6]. 
gender's limit. Concurrently, it is also meant to control the women's attitude as they walk to the 'serambi' to serve food and delicacies. The ethic of women is the main concern. As most of them wear the 'sarung', large clothes that wrapped the bottom part of the body, the speed of walking may affect the level of decency. Walking in hesitation should be avoided and can be perceived as impolite. Hence, the leveling implicitly becomes a device of manner $[2,7,8]$.

'Rumah Ibu' is a private place, designated only for the family and their honorable guests. It is an open space with minimal enclosure or partition. The spaces are widely open. However, justifications of activities are defined by means of platform, which is, represented by the 'mengkuang mat', a woven mat made from the 'mengkuang leaves'. This mat is a device that invents the domestic ritual. Every activity is held on it, ranging from sleeping, sitting, dining and working. It promotes the boundaries between different activities in one space. The status of visitors can also be determined by the quality of this mat, which normally appears during special occasions. The degree of open spaces in 'Rumah Ibu' can be also be controlled by means of 'curtain' that explicitly split a space into smaller units, hence separating the genders among family members, while enhancing the sense of respect and privacy $[2,7,8]$.

The kitchen and 'selang' are solely conceived as a woman's sphere. These are the places for the women to gather and chat, apart from cooking and resting. In the kitchen, all the utensils are assembled on shelves, one of the earliest furniture representations in the Malay house. Still, the preparation is done on the floor. If one looks into the main kitchen equipment, coconuts are grated by using a grating device that requires sitting; flour is made by rolling a stone while sitting, and onions are crunched using stone mortar/pestle in a sitting position. While the ladies work entirely in the kitchen, teenage girls are urged to help in preparing the dishes. They are forced to do so in order to inherit the traditions and manners in cooking and serving, while learning the secret 'maternal' ingredients that is vital as they proceed into the marriage sphere. After all, a perfect wife is measured by her ability to perform household and domestic routine $[2,7,8]$.

The scenarios explained above correspond to specific rituals $[9,10]$. Thus, two rituals have a direct root to the study of Malay domestic space;

1. Gender Segregation Ritual (Figure 2)

All internal spaces were designed based on genders. Segregation, as implemented by Islamic teaching is vital in Malay's ethical code $[2,11]$.

2. Sitting Ritual (Figure 3)

Traditional house by itself is perceived as furniture [4]. This assumption is supported by the construction of its wall, floor and openings where sitting is promoted through sitting-based artifacts, and gradually became an ethical conduct for Malays.

The assistance of rituals' artifacts allows the ritual to be alive. In modern context, it is proposed that the rituals are no longer attached to nostalgic surrounding which is the traditional house. In fact, it relied on an abstraction disseminated by the ritual's artifact around the occupants. Based on observation, these three elements are the relics of the past $[9,10]$, the rituals' artifacts that canonized the ancient rituals practiced by the ancestors: 
1. 'Mengkuang Mat' (Figure 3) [2];

2. Curtain;

3. Serambi/Deck.

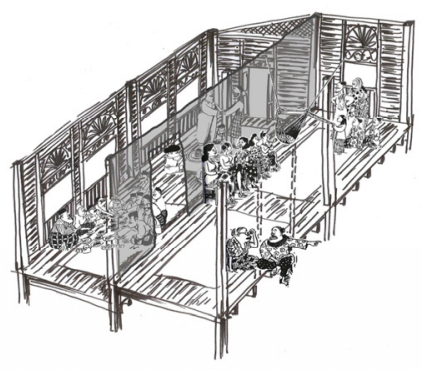

(a)

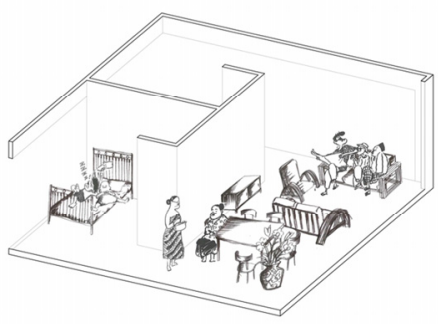

(d)

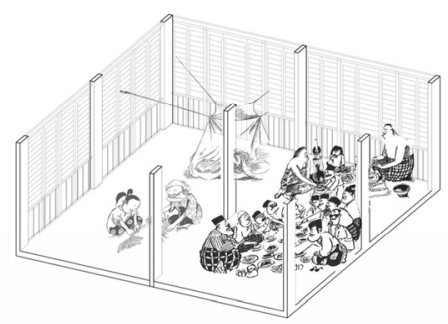

(b)

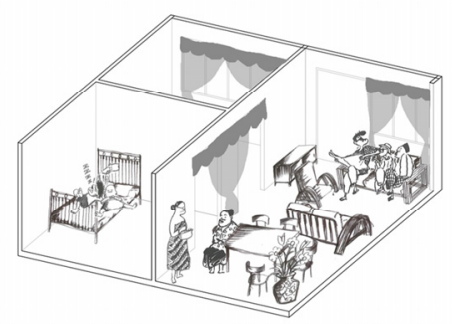

(c)

Figure 2: Sample of the evolution of gender segregation in a Malay house. Clockwise: (a) traditional house; (b) 1940, colonial house; (c) 1980, terrace house; (d) 2000, apartment.

\subsection{Malay's precedence}

The three elements discussed earlier signify the embedded rituals of the traditional Malay house. They highlight the epitome of Malay rituals in the absence of nostalgic realm; the moment when nothing represents the traditionalistic sense [9]. In the modern context, although these elements exist in a different material; these still unleash the effect of rituals, demonstrating that the hypothesis can be defended. This phenomenon is briefly established through the lenses of caricature made by Lat, one of Malaysia's prominent cartoonists. In his masterpiece 'Kampung Boy' [12], Lat explained the life of an ordinary village boy in the year of 1950 , a few years before Independence. The environments portray the traditional rituals and cultures in their original state. The traditional Malay house acts as his background, where the everyday life is projected. Lat also used to project the sequel of the comic through 'Town Boy' [13], telling of the protagonist's teenage life in an urban setting during post-Independence era.

In this comic, the opposition between living in the village and town, and the advent of modern housing had influenced the lifestyle of the Malays, particularly for the protagonist in the story. 


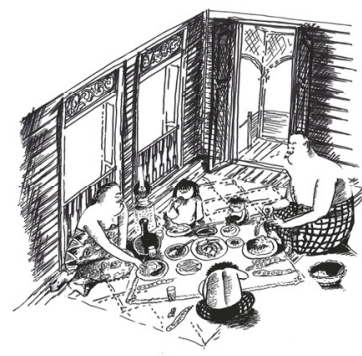

(a)

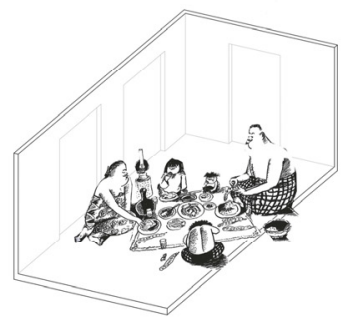

(b)

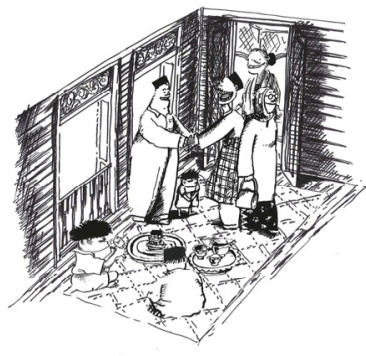

(c)

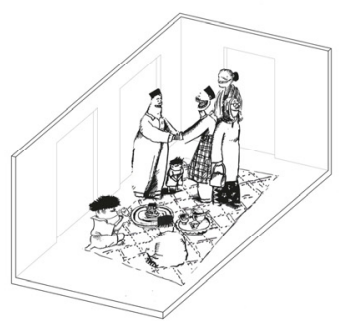

(d)

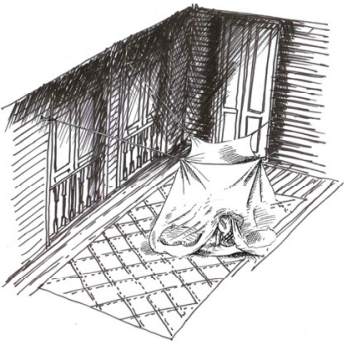

(e)

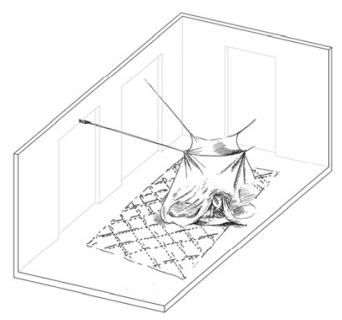

(f)

Figure 3: Sample of the evolution of sitting ritual and its relation to artifact; 'Mengkuang Mat' in a Malay house. Upper figures (a), (c) and (e) represent traditional realm, lower figures (b), (d) and (f) show the modern scenarios. Several activities are demonstrated; dining (a) and (b); welcoming guest (c) and (d), sleeping (e) and (f).

Yet in 'Kampung Boy: Yesterday and Today' [14], Lat criticised the values and perception of the modern Malay, which eventually act as a wake-up call for the Malay society on how they have been enculturing and adapting modern life and the traditional values. Hence, the comics are non-fictional evidence of the performance of the rituals as they precisely described the way the Malays perceive their life and habits through time. The three comics were the basis of research. Though there are plenty of scholarly references such as the Malay Annal and 'Misa Melayu' [2], the subject that was described focused more onto the aristocratic lineage, which has been bestowed with rigorous custom and rituals as compared to the commoners' life. The common rituals artifacts are simply the anecdote of commoners; emanating the ordinary lifestyle of most of the Malays. With this paradigm, Lat expressed the objects in most of his graphics, which in return speculate the life of modern Malay's family.

\section{The manifestoes}

Therefore, the idea to make a journey of rituals around the ordinary object and space is formed. By taking the layout of existing modern apartments in Kuala Lumpur as the basis and using these as critics towards the modern condition [3], 
the modern performance of Malay's ritual in three different settings that stimulates different stories on how the rituals are spatially practiced is represented [15]. The settings are then characterised by simple themes that summarise the intention. These are:

1. Who is your best friend? (Figure 4(a))

2. Secret Recipe (Figure 4(b))

3. Hide and Seek (Figure 4(c))

Lat's characters are vital in acknowledging the scenarios that were investigated. As such, the characters become the actors that enhance the scenarios. A single Malay family was portrayed as the ritual's performers.

\subsection{Who is your best friend?}

The first setting is a story of two 'serambis' or reception decks, arranged in opposite to the central corridor of a typical Malaysian apartment. The setting aims, in particular, to draw an explicit line of guest segregation, and implicitly marked the gender separation. The attributes between the two 'serambis' create an anomaly, as one stood open and the other finds its place behind a glass frame; one promotes bare-footing before the main door and the other allows you to walk past the door in your shoes. The oppositions between open and close gesture demonstrate different levels of social relation and sense of respect between the two families, justifying the variance of semi-public and semi-private space, friends and best buddy. Various positions between the two 'serambis' compliment social strata in the Malay society. Once the relation gets closer, the thought behind gender segregation becomes irrelevant (Figure 4(a)).

\subsection{The secret recipe}

The second setting is a centralised kitchen cabinet, which takes its position in the middle of an open plan apartment. The setting aims to question the various implications of rituals in the Malays' dining etiquette. The duality of kitchen surface allows the sitting rituals to represent specific routine. Beginning from a sitting platform for preparation, the surface is converted into a cooking countertop, which then transforms into dining table and finally into a dining platform. In the preparation zone, the platform accentuates the Malays' habits in preparing food collectively. Meanwhile in the dining area it encourages the culture of eating food by hand. The fact that it is a centralised kitchen is a critique on the rituals of gender segregation, as it moves beyond its encapsulated domain into a universal space. However, this flexible compartment still supports and breeds decency. Hence, for Malays, the secret of being 'decent' is always initiated from the kitchen, as this is the place where a mother moulds her children (Figure 4(b)).

\subsection{Hide and seek}

The third setting relates to the curtain, which becomes a design element for the children's room. This object intends to substitute the internal wall, and provides possible expansion for a bigger family. The curtain acts as a veil. It highlights the seclusion of genders among children, as well as making enclosure to the most 


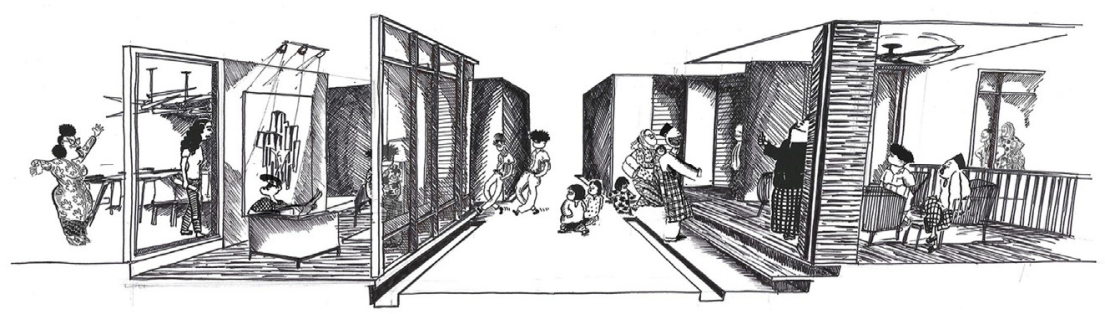

(a)

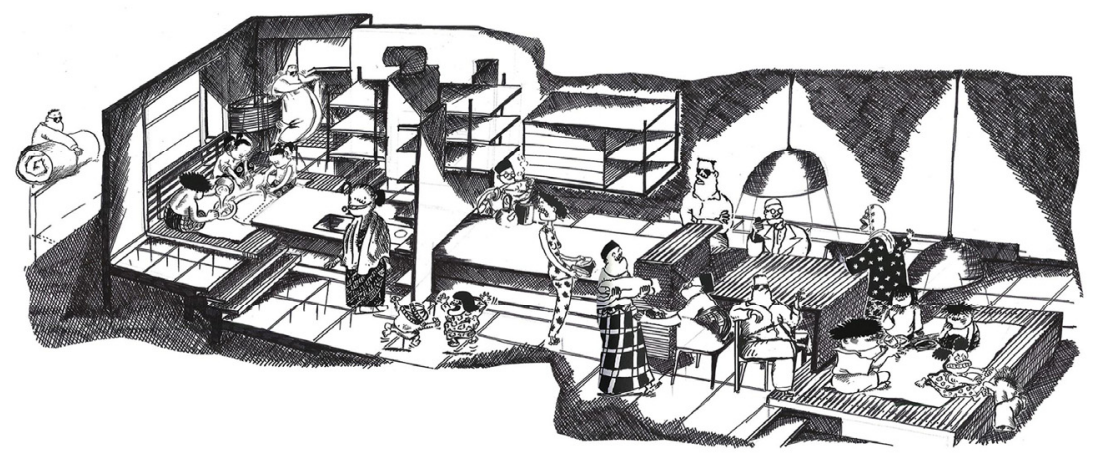

(b)

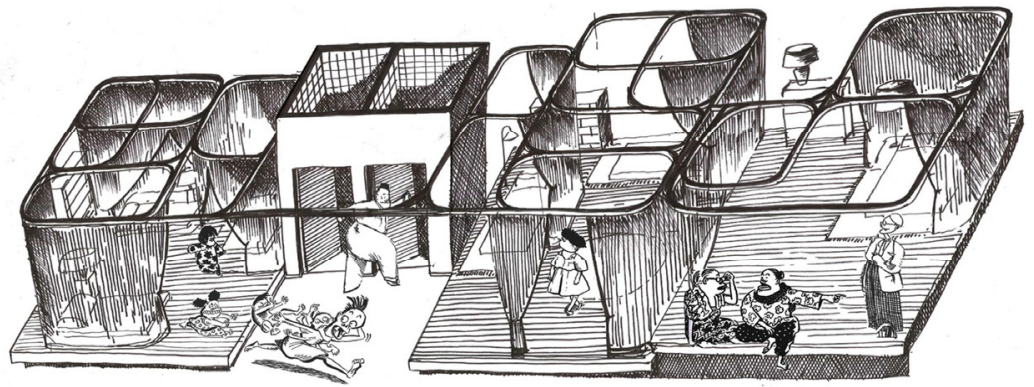

(c)

Figure 4: Three manifestoes are created based on the existing rituals. Who is Your Best Friend? (a), Secret Recipe (b) and Hide and Seek (c).

private zone in a house, which is the bathroom. At the same time, its attributes may integrate two open spaces. The opposition between seclusion and integration creates a meaning towards privacy and respectability. Hence, the curtain is the ultimate instrument of rituals, as it blurs it beyond its purpose. As for the children, the more you hide something, the more they are going to seek for it (Figure 4(c)).

\section{The new paradigm}

The elements suggest that rituals can no longer be manifested through nostalgic sentiment of the past [9], but rather to be demonstrated within the modern environment itself. If one look through their attributes, the elements represent a 


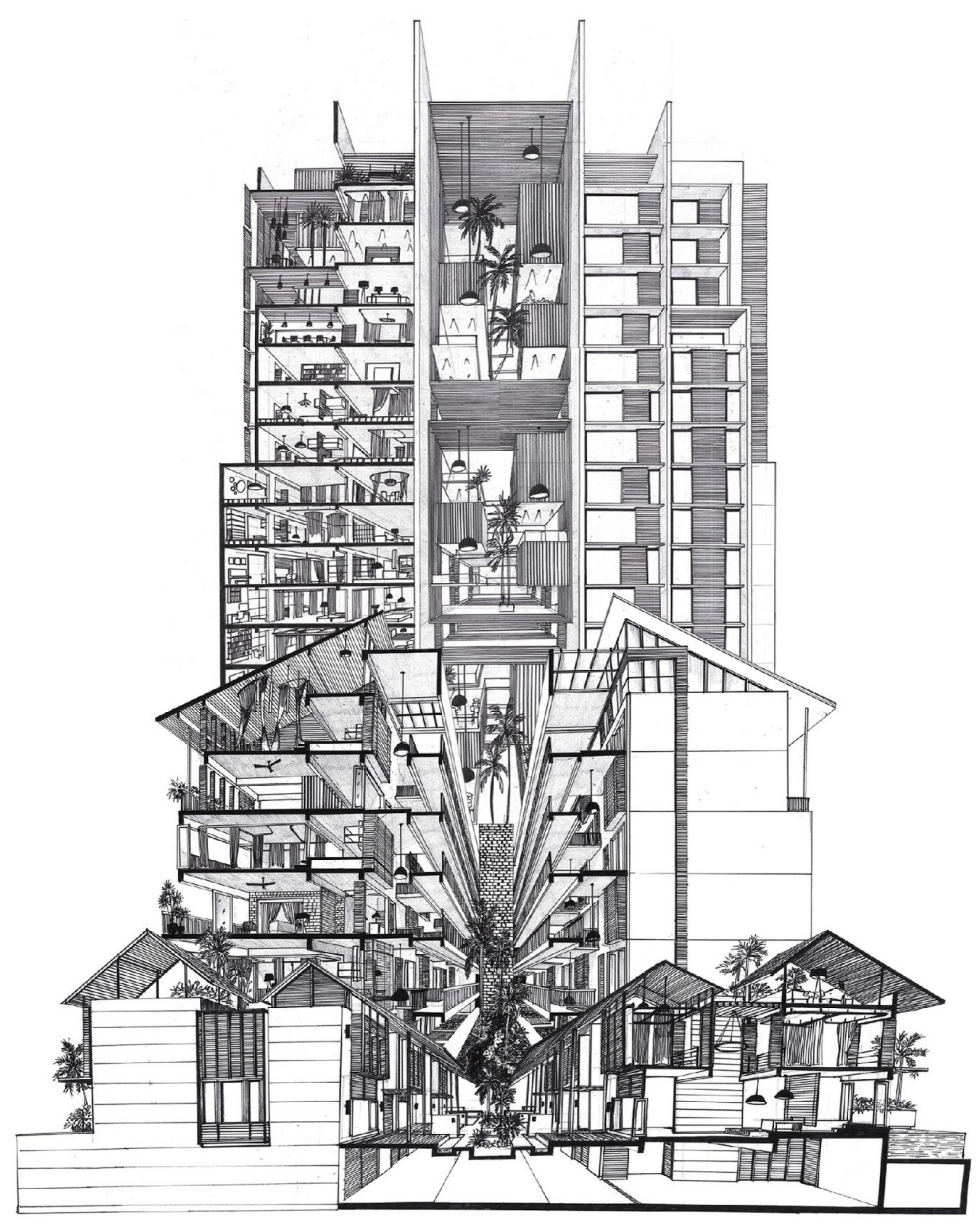

Figure 5: The manifestoes are tested in 3 new developments in Kuala Lumpur. The bottom image is a low-rise development, the middle image shows a mid-rise development and the upper image represents a high-rise project.

single-family dwelling that is arranged in tripartite spaces; living, dining, and bedroom [3]. Diversifying these spaces allow a derivation of a type of housing. Thus, the three elements act as manifesto in rethinking the rituals in the modern Malay house. However, the context of 'modern Malay house' is related within the cityscape and urban setting which has become the initial platform in synthesizing the manifesto. As such, this scenario indicates the main focus of this study, i.e. to analyse the modern houses within a dense urban fabric specifically in Kuala Lumpur. A single landed house may provide a similar effect of a traditional house. However, a high-rise housing may trigger a different scenario. Hence, the manifestoes are further developed into three different-scaled projects, which are the low, medium and high-density housing (Figure 5). 
If one noticed, the introduction of the first element, which is the 'serambi' or reception, has very much changed the architectural quality of a building. It may increase the floor area. More importantly it allows for a more sociable space, that implicitly ignites the atmosphere of a village. The second and third elements, which are the island kitchen and curtain, may be varied in accordance to the size of the house itself. They compliment the idea of open spaces within standardised structures and layout. Hence a completed housing project may not necessarily be equipped with a permanent wall and side cabinets. This tends to offer more flexibility and environmental sustainability, which is good for a huge family. After all, they also prompt for different perspectives of a housing scheme by the developer, which in return will always be beneficial to the society.

The adaptation of the manifestoes into real projects $[3,16]$ shows that this idea can be further developed into a realistic scheme. Although the scenarios may be exaggerations of reality, this allows the Malays to realize that rituals are part of their daily routine, no matter where and when they are performed. Perhaps the agenda towards 'decent' [17], Malays allow the rituals to be perpetually significant in time. In fact, it becomes an ultimate tool in cultivating the new generation of Malays with rich pro-social behaviour who ultimately, takes responsibility over their environment.

\section{References}

[1] Alexander, Christopher et al. A Pattern Language: Town. Building Construction. California; Oxford University Press, 1977

[2] Rasdi, Tajuddin et al. The Architectural Heritage of The Malay World; The Traditional Houses. Johor: Universiti Teknologi, Malaysia, 2005

[3] Lerup, Lars. Planned Assaults: The Nofamily House, Love/House, Texas Zero. Montreal: Canadian Centre for Architecture, 1987

[4] Gibbs, Phillip et al. Building A Malay House. New York; Oxford University Press, 1987

[5] Chang, Jiat-Hwee. "Natural" Traditions: Constructing Tropical Architecture in Transnational Malaysia and Singapore. Explorations: Volume 7 - Issue 1, Spring 2007

[6] Markus, Thomas. A. Building and Power: Freedom and Control in the Origin of Modern Building Types. London; Routledge, 1993

[7] Hashim, Ahmad Hariza et al. "Urban Malays - User Bahaviour and Perspective on Privacy and Spatial Organization for Housing”, Volume 3, Issue 1. Archnet-IJAR, International Journal of Architecture Research, 2009

[8] E. Hosseini et al. Design Values in Traditional Architecture: Malay House. 6th International Seminar on Vernacular Settlements, Contemporary Vernaculars: Places, Processes and Manifestations. Famagusta, North Cyprus; 2012

[9] Frampton. K. Towards A Critical Regionalism: Six Points For An Architecture of Resistance, in The Anti-Aesthetic. Essays on Postmodern Culture edited by Hal Foster. Seattle; Bay Press, 1983 
[10] Ruegg, Arthur. S. Klaus. Le Corbusier: Furniture and Interiors 1905 1965. Zurich; Verlag Scheidegger \& Spiess AG, 2012

[11] Al-Attas, Syed Muhammad Naquib. Islam and Secularism. Kuala Lumpur; International Institute of Islamic Thought and Civilization, 1993

[12] Mohammad Nor, Khalid. The Kampung Boy. Kuala Lumpur; Berita Publishing, 1979

[13] Mohammad Nor, Khalid. The Town Boy. Petaling Jaya; MPH Publishing, 2014

[14] Mohammad Nor, Khalid. Kampung Boy: Yesterday and Today. Petaling Jaya; MPH Publishing, 2014

[15] Hobsbawm, Eric et al. The Invention of Tradition. Cambridge: University Press, 1993

[16] Cornellissen, Hans et al. Dwelling As A Figure of Thought. Amsterdam; Sun Publisher, 2005

[17] Freadman, R. "Decency and its Discontents", 28.2, 393-405, Philosophy and Literature, 2004 